\title{
Changes in rumen microbiota composition and in situ degradation kinetics during the dry period and early lactation as affected by rate of increase of concentrate allowance
}

\author{
K. Dieho, ${ }^{* 1}$ B. van den Bogert, $†$ G. Henderson, $\ddagger$ A. Bannink,§ J. Ramiro-Garcia, $†$ H. Smidt, $†$ and J. Dijkstra* \\ ${ }^{*}$ Animal Nutrition Group, Wageningen University and Research, PO Box 338, 6700 AH Wageningen, the Netherlands \\ †Laboratory of Microbiology, Wageningen University and Research, PO Box 8033, 6700 EJ Wageningen, the Netherlands \\ $\ddagger$ Grasslands Research Centre, AgResearch Limited, Palmerston North 4442, New Zealand \\ §Animal Nutrition, Wageningen Livestock Research, Wageningen University and Research, PO Box 338, 6700 AH Wageningen, the Netherlands
}

\section{ABSTRACT}

Changes in rumen microbiota and in situ degradation kinetics were studied in 12 rumen-cannulated Holstein Friesian dairy cows during the dry period and early lactation. The effect of a rapid (RAP) or gradual (GRAD) postpartum (pp) rate of increase of concentrate allowance was also investigated. Cows were fed for ad libitum intake and had free access to a mixed ration consisting of chopped wheat straw (dry period only), grass silage, corn silage, and soybean meal. Treatment consisted of either a rapid (1.0 kg of dry matter $/ \mathrm{d} ; \mathrm{n}=6)$ or gradual $(0.25 \mathrm{~kg}$ of dry matter $/ \mathrm{d} ; \mathrm{n}=6)$ increase of concentrate allowance (up to $10.9 \mathrm{~kg}$ of dry matter/d), starting at $4 \mathrm{~d}$ pp. In whole rumen contents, bacterial community composition was assessed using samples from 50, 30, and $10 \mathrm{~d}$ antepartum (ap), and 3, 9, 16, 30, 44, 60, and $80 \mathrm{~d}$ pp, and protozoal and archaeal community composition using samples from $10 \mathrm{~d}$ ap, and 16 and $44 \mathrm{~d}$ pp. Intake of fermentable organic matter, starch, and sugar was temporarily greater in RAP than GRAD at $16 \mathrm{~d}$ pp. Bacterial community richness was higher during the dry period than during the lactation. A rapid increase in concentrate allowance decreased bacterial community richness at 9 and $16 \mathrm{~d}$ pp compared with a gradual increase in concentrate allowance, whereas from $30 \mathrm{~d}$ pp onward richness of RAP and GRAD was similar. In general, the relative abundances of Bacteroidales and Aeromonadales were greater, and those of Clostridiales, Fibrobacterales, and Spirochaetales were smaller, during the lactation compared with the dry period. An interaction between treatment and sampling day was observed for some bacterial community members, and most of the protozoal and archaeal community members. Transition to lactation increased the relative abundance of Epidinium and Entodinium, but reduced

Received September 10, 2016

Accepted December 28, 2016.

${ }^{1}$ Corresponding author: kasper.dieho@wur.nl the relative abundance of Ostracodinium. Archaea from genus Methanobrevibacter dominated during both the dry period and lactation. However, during lactation the abundance of the methylotrophic Methanomassiliicoccaceae and Methanosphaera increased. The in situ degradation of organic matter, neutral detergent fiber, starch, and crude protein was neither affected by treatment nor by transition from the dry period to lactation. Results show that the composition of the rumen microbiota can change quickly from the dry period to the lactation period, in particular with a rapid increase in fermentable substrate supply postpartum, but this was not associated with changes in rumen degradation kinetics.

Key words: transition period, dairy cattle, rumen microbiome or microbiota, rumen adaptation

\section{INTRODUCTION}

Ruminants are characterized by the presence of a highly developed forestomach, the reticulorumen, which harbors a complex microbial ecosystem. Rumen microbiota ferment OM, yielding microbial biomass and VFA as fermentation end products. These cover a significant part of the energy (Bergman, 1990) and protein (Tamminga et al., 1994) requirement of the ruminant host. The rumen microbiota is highly diverse, especially within the domain bacteria (Edwards et al., 2004; Kim et al., 2011), and its composition depends on the type and quantity of substrates ingested and on the host species and its physiological status (McCann et al., 2014; Henderson et al., 2015). The type and quantity of substrate consumed leads to changes in the rate of substrate fermentation, rumen VFA concentrations, $\mathrm{pH}$, passage rate, and the composition of the microbiota (Fernando et al., 2010; Belanche et al., 2012). However, the capacity to ferment a wide range of substrates is likely to be maintained despite changes in microbiota community composition as a high degree of functional redundancy and resilience coincides with 
the diversity of the microbiota (Henderson et al., 2015; Weimer, 2015).

In many dairy systems, the transition from dry period to lactation is associated with large dietary changes. Typically, a dry cow has a low DMI and a fiber-rich ration of relatively poor digestibility, whereas during early lactation DMI increases and rations are rich in readily fermentable carbohydrates (structural and nonstructural). Various studies addressed the interrelationship between ration composition and the composition of the rumen microbiota (reviewed by McCann et al., 2014). However, few studies (Mohammed et al., 2012; Pitta et al., 2014; Lima et al., 2015) focused on the transition period in dairy cattle, and knowledge of rumen microbiota changes during this period is limited. In addition, the idea of functional redundancy requires the study of changes in the microbiota together with measurements of substrate degradation capacity by the microbiota to understand the functional effect of any changes in microbiota community composition. This combination of measurements in the transition period is rarely reported.

Therefore, the primary aim of the present experiment was to study the effects of ration changes associated with transition from the dry period to lactation, and the effect of rate of concentrate build-up treatments during the early lactation, on shifts in the ruminal microbiota and on in situ degradation characteristics of OM, starch, NDF, and CP. Transition from the dry period to lactation was hypothesized to change the rumen microbiota composition after calving. In addition, a transient effect of the concentrate build-up strategy on the ruminal microbiota composition was expected. Effects on the capacity of the rumen microbiota to degrade OM, starch, NDF, and CP were hypothesized to be minor only due to the large degree of functional redundancy of the rumen microbial community. We previously reported results from the same experiment showing that the large postpartum increase in daily fermentable organic matter (FOM) intake coincided with an increase in daily VFA production and fractional VFA absorption rate (Dieho et al., 2016b), and an increase in rumen papillae surface area (Dieho et al., 2016a). Moreover, papillae surface area increased faster when increasing the daily concentrate allowance at a rapid rate compared with that at a gradual rate (Dieho et al., 2016a). However, the fractional VFA absorption rate was not affected by the concentrate treatments (Dieho et al., 2016b).

\section{MATERIALS AND METHODS}

The experimental procedures were approved by the Animal Care and Ethics Committee of Wageningen UR (protocol 2012030b) and conducted under the Dutch Law on the Animal Experiment.

\section{Animals, Experimental Design, Rations, and Treatment}

The experiment has been described in detail by Dieho et al. (2016a). Briefly, 12 rumen-cannulated, first parity Holstein Friesian dairy cows were dried off $8 \mathrm{wk}$ before expected calving date and entered the experiment. Samples were collected during the pretreatment period at 50, 30, and $10 \mathrm{~d}$ antepartum (ap) and $3 \mathrm{~d}$ postpartum (pp), and during the treatment period at $9,16,30,44,60$, and $80 \mathrm{~d} \mathrm{pp}$. In situ degradation series started $14 \mathrm{~d}$ ap (pretreatment), and at 18, 46, and $62 \mathrm{~d}$ pp (treatment period).

Cows received either a dry-period ration or basal lactation ration that was fed once a day for ad libitum intake, and had free access to water. The dry period ration $(603 \mathrm{~g}$ of $\mathrm{DM} / \mathrm{kg}$ ) consisted of $27 \%$ grass silage, $27 \%$ maize silage, $11 \%$ soybean meal, and $35 \%$ chopped wheat straw (DM basis), containing $920 \mathrm{~g}$ of OM, $553 \mathrm{~g}$ of NDF, $325 \mathrm{~g}$ of ADF, $32 \mathrm{~g}$ of ADL, $109 \mathrm{~g}$ of $\mathrm{CP}, 90 \mathrm{~g}$ of starch, and $44 \mathrm{~g}$ of sugar per $\mathrm{kg}$ of DM, providing 5.3 MJ of $\mathrm{NE}_{\mathrm{L}}$ (van Es, 1978) and $455 \mathrm{~g}$ of rumen FOM (Tamminga et al., 1994) per $\mathrm{kg}$ of DM. Dry period minerals were provided $(140 \mathrm{~g} / \mathrm{cow}$ per d; DairyFit Droogstand Vitaal, Pre-Mervo, Utrecht, the Netherlands), containing $751 \mathrm{~g}$ of ash, $39 \mathrm{~g}$ of CP, 20 $\mathrm{g}$ of $\mathrm{Ca}, 30 \mathrm{~g}$ of P, $35 \mathrm{~g}$ of Na, $250 \mathrm{~g}$ of $\mathrm{Mg}, 25 \mathrm{~g}$ of $\mathrm{S}$, $2,200 \mathrm{mg}$ of $\mathrm{Cu}, 3,300 \mathrm{mg}$ of $\mathrm{Zn}, 3,000 \mathrm{mg}$ of $\mathrm{Mn}, 35 \mathrm{mg}$ of Co, $100 \mathrm{mg}$ of I, $35 \mathrm{mg}$ of Se, 400,000 IE of vitamin A, 125,000 IE of vitamin D, and 10,000 IE of vitamin E per $\mathrm{kg}$ of DM. The basal lactation ration (466 g of DM/ $\mathrm{kg}$ ) consisted of $42 \%$ grass silage, $41 \%$ maize silage, and $17 \%$ soybean meal (DM basis), containing $925 \mathrm{~g}$ of $\mathrm{OM}, 392 \mathrm{~g}$ of NDF, $235 \mathrm{~g}$ of ADF, $16 \mathrm{~g}$ of ADL, 157 $\mathrm{g}$ of CP, $139 \mathrm{~g}$ of starch, and $67 \mathrm{~g}$ of sugar per $\mathrm{kg}$ of $\mathrm{DM}$, providing $6.7 \mathrm{MJ}$ of $\mathrm{NE}_{\mathrm{L}}$ and $561 \mathrm{~g}$ of $\mathrm{FOM}$ per $\mathrm{kg}$ of DM. Lactation minerals were provided (180 g/ cow per d; DairyFit Lactatie $\mathrm{nP}$, Pre-Mervo) containing $940 \mathrm{~g}$ of ash, $2 \mathrm{~g}$ of CP, $155 \mathrm{~g}$ of $\mathrm{Ca}, 0 \mathrm{~g}$ of P, 75 $\mathrm{g}$ of $\mathrm{Na}, 120 \mathrm{~g}$ of $\mathrm{Mg}, 40 \mathrm{~g}$ of S, 1,200 $\mathrm{mg}$ of $\mathrm{Cu}, 1,500$ $\mathrm{mg}$ of $\mathrm{Mn}, 1,500 \mathrm{mg}$ of $\mathrm{Zn}, 45 \mathrm{mg}$ of Co, $100 \mathrm{mg}$ of I, $34 \mathrm{mg}$ of Se, 500,000 IE of vitamin A, 65,000 IE of vitamin $\mathrm{D}$, and 5,000 IE of vitamin $\mathrm{E}$ per $\mathrm{kg}$ of DM. From 0 to $3 \mathrm{~d}$ pp, $0.9 \mathrm{~kg}$ of DM/d concentrate was fed. Thereafter, concentrate treatment started consisting of either a rapid (RAP; $1.0 \mathrm{~kg}$ of $\mathrm{DM} / \mathrm{d}$ ) or a gradual (GRAD; $0.25 \mathrm{~kg}$ of DM/d) increase of concentrate allowance up to $10.9 \mathrm{~kg}$ of $\mathrm{DM} / \mathrm{d}$, irrespective of rate of increase. The concentrate $(892 \mathrm{~g}$ of $\mathrm{DM} / \mathrm{kg})$ consisted of $212 \mathrm{~g}$ of sugar beet pulp, $200 \mathrm{~g}$ of maize gluten, 150 $\mathrm{g}$ of barley, $150 \mathrm{~g}$ of wheat, $120 \mathrm{~g}$ of soybean meal, 100 
$\mathrm{g}$ of citrus pulp, $35 \mathrm{~g}$ of molasses, $20 \mathrm{~g}$ of vinasse, $8 \mathrm{~g}$ of chalk, $3 \mathrm{~g}$ of salt, and $2 \mathrm{~g}$ of mineral premix per $\mathrm{kg}$ of DM and contained $932 \mathrm{~g}$ of OM, $252 \mathrm{~g}$ of NDF, 115 $\mathrm{g}$ of ADF, $8 \mathrm{~g}$ of ADL, $178 \mathrm{~g}$ of CP, $248 \mathrm{~g}$ of starch, and $95 \mathrm{~g}$ of sugar per $\mathrm{kg}$ of DM providing 7.4 MJ of $\mathrm{NE}_{\mathrm{L}}$ and $682 \mathrm{~g}$ of FOM per $\mathrm{kg}$ of DM. Daily intake of dry period or basal lactation ration and concentrate $(\mathrm{kg} / \mathrm{d})$ was measured individually. The concentrate was individually fed using a concentrate dispenser (Manus VC5, DeLaval, Steenwijk, the Netherlands), and made available in equal portions over six 4 -h periods. Daily management and housing conditions, and feed intake measurements, feed sampling, and chemical analysis of feed samples are described in detail by Dieho et al. (2016a).

\section{Rumen Content Sampling}

Rumen contents were completely evacuated on all sampling days (Dieho et al., 2016a). Just before starting the evacuation, a rumen fluid sample was taken from the ventral rumen sac for determination of the VFA concentration and composition. After evacuation of approximately half of the rumen contents, a sample of whole rumen content was taken (Henderson et al., 2015 ), immediately placed on ice and stored at $-20^{\circ} \mathrm{C}$ until further processing. After freeze-drying, samples were ground to pass a 1-mm screen (100AN, Peppink Mills BV, Olst, the Netherlands). Rumen $\mathrm{pH}$ was continuously measured during the VFA production measurements as reported previously (Dieho et al., 2016b).

\section{Profiling Rumen Bacterial Community}

The DNA extraction and profiling is described in detail in Supplemental Methods S1 (https://doi. org/10.3168/jds.2016-11982). Briefly, DNA was extracted by mixing $50 \mathrm{mg}$ of freeze-dried rumen content in a microfuge tube containing $180 \mathrm{mg}$ of macaloid suspension (Zoetendal et al., 2006), $50 \mu \mathrm{L}$ of $10 \%$ SDS (Invitrogen, Carlsbad, CA) and 0.1-mm zirconium beads. The solution was mixed with $500 \mu \mathrm{L}$ of acid phenol (Invitrogen, Thermo Fisher Scientific, Waltham, MA), followed by 3 Fastprep (Bertin Technologies, Montigny le Bretonneux, France) treatments at $5.5 \mathrm{~m} / \mathrm{s}$ for $45 \mathrm{~s}$ with cooling on ice for $90 \mathrm{~s}$ between treatments to effect mechanical cell disruption. Purified bacterial DNA was extracted using a modified version (Zoetendal et al., 2006; van den Bogert et al., 2013) of the QIAamp DNA Stool Mini Kit protocol (Ambion, Waltham, MA). The quantity and quality of obtained DNA was assessed using a NanoDrop ND-1000 spectrophotometer (Nanodrop Technologies, Wilmington, DE) and electrophoresis on a 1\% (wt/vol) agarose gel. For $16 \mathrm{~S}$
rRNA gene-based microbial composition profiling, barcoded amplicons from the V1-V2 region of $16 \mathrm{~S}$ rRNA genes were generated using a 2-step PCR strategy that reduces the effect of barcoded primers on the outcome of microbial profiling (Berry et al., 2011; Tian et al., 2016). Purified PCR products were mixed in equimolar amounts and resulting pools underwent adaptor ligation followed by sequencing on the MiSeq platform with addition of $20 \%$ PhiX (GATC-Biotech, Konstanz, Germany). The 16S rRNA gene sequencing data were analyzed using NG-Tax (Ramiro-Garcia et al., 2016). Operational taxonomic units (OTU) were defined using an open reference approach, and taxonomy was assigned to those OTU using the SILVA $16 \mathrm{~S}$ rRNA gene reference database (Quast et al., 2013).

\section{Profiling Rumen Protozoal and Archaeal Communities}

Freeze-dried samples of whole rumen content from 10 d ap, and 16 and $44 \mathrm{~d}$ pp, were shipped to AgResearch (Palmerston North, New Zealand) for processing as part of the Global Rumen Census project (Henderson et al., 2015). Briefly, after DNA extraction using the PCQI method described by Rius et al. (2012), and PCR amplification described by Henderson et al. (2015), archaeal 16S rRNA and protozoal 18S rRNA genes were sequenced using 454 GS FLX Titanium chemistry (Eurofins MWG Operon, Ebersberg, Germany). Pyrosequence data were processed using QIIME (version 1.8; Caporaso et al., 2010) and grouped into OTU sharing over $99 \%$ sequence similarity for archaea and $100 \%$ for protozoa. Sequence data were assigned to phylogenetic groups using the Basic Local Alignment Search Tool (Altschul et al., 1990) against RIM-DB version 13_11_13 (Seedorf et al., 2014) for archaea and an AgResearch in-house database (Kittelmann and Janssen, 2011) for protozoa. Archaea were assigned at the species level, protozoa at the genus level.

\section{In Situ Degradation}

The fractional degradation rate of OM, starch, NDF, and $\mathrm{CP}$ was evaluated 4 times in the same cows from each treatment group (3 each) using an all-out in situ method adapted from Tas et al. (2006). In short, for each incubation series, 4 polyamide bags $(8.5 \times 16.5$ cm; 40- $\mu \mathrm{m}$ pore size; PA 40/30, Nybolt, Zurich, Switzerland) each containing $3.0 \mathrm{~g}$ of soybean hulls and 3.0 $\mathrm{g}$ of ground corn (both ground to pass a 3 -mm screen; $5.7 \mathrm{~g}$ of DM per bag) were incubated for $72,48,24,8$, and $4 \mathrm{~h}$. After recovery from the rumen, the bags were immediately placed in iced water. After gently rinsing with tap water, the bags were washed for 40 min us- 
ing $58 \mathrm{~L}$ of cold water with a wool program without centrifuging (Öko Turnamat 2800, AEG Hausgeräte, Nürnberg, Germany) including 4 nonincubated bags (0 h) for determination of the washable $(\mathbf{W})$ fraction. In addition, 4 bags were incubated for $336 \mathrm{~h}$ in each cow for the determination of the undegradable $(\mathbf{U})$ fraction. After washing, bags were stored at $-20^{\circ} \mathrm{C}$ before forced air oven drying $\left(60^{\circ} \mathrm{C}\right.$, overnight). After drying, samples were acclimatized to air and weighed. Residues were pooled per incubation time for each cow and incubation series, and ground to pass a 1-mm screen (ZM1, Retsch GmbH, Haan, Germany). Residues were analyzed for DM (ISO, 1999), ash (ISO, 2002), starch (ISO, 2004), $\mathrm{N}$ (ISO, 2005), and NDF (with heat stable $\alpha$-amylase; Van Soest et al., 1991) using an Ankom 2000 Fiber Analyzer (Ankom Technology Corp., Macedon, NY). The fractional degradation rate $\left(\boldsymbol{k}_{\mathrm{d}}, / \mathrm{h}\right)$ of the potentially degradable fraction of starch and $\mathrm{N}$ was calculated according to the first-order model of Robinson et al. (1986):

$$
R t=U+D \times \exp \left(-k_{\mathrm{d}} \times t\right),
$$

where $R t$ is the residual at time $t, U$ is the rumen undegradable fraction, $D$ is the potentially degradable fraction $(D=1-W-U)$, and $t$ the time of incubation (h). For starch, the U-fraction was assumed to be zero. For NDF and OM the model included a lag time $(L$, h) with

$$
R t=U+D(t \leq L)
$$

and

$$
R t=U+D \times \exp \left[-k_{\mathrm{d}} \times(t-L)\right](t>L) .
$$

For NDF, the W-fraction was assumed to be zero.

\section{Calculations and Statistical Analysis}

The similarity in bacterial community composition between samples was assessed by principal coordinate analysis using the weighted UniFrac metrics (Lozupone et al., 2007) in QIIME (v1.2; Caporaso et al., 2010). The phylogenetic diversity-whole tree (Faith, 1992) richness metric of the bacterial community was calculated 10 times for each sample using 5,000 randomly selected reads. Sample averages of the phylogenetic diversitywhole tree richness metric were analyzed. Bacterial taxa were summarized at the order level, and bacterial taxa with a relative abundance of $>1.0 \%$ in more than $>20.0 \%$ of the samples at the genus or family rank were considered major taxa and summarized separately. All other taxa were grouped under "Others." The association scores between the major taxa and rumen fluid and feed intake variables (reported by Dieho et al., 2016a,b) were explored using regularized canonical correlation analysis (González et al., 2012) and visualized as a heatmap as described by Henderson et al. (2015).

All feed and rumen fluid variables, protozoal, archaeal, and major bacterial taxa, and in situ incubation variables were assumed to be related to sampling day and treatment. Data were analyzed using a MIXED model (Littell et al., 2006) in SAS 9.2 (SAS Institute Inc., Cary, NC):

$$
Y_{i j}=\mu+T_{i}+D_{j}+(T \times D)_{i j}+e_{i j}
$$

where variable $Y_{i j}$ was dependent on $\mu$ as the average experimental value and fixed main effects of concentrate treatment $T_{i}(i=\mathrm{RAP}, \mathrm{GRAD})$, sampling day $D_{j}(j=-50, \ldots, 80$ for bacteria; or $-10,16$, and 44 for protozoa and archaea; or $-14, \ldots, 62$ for the in situ incubations), and fixed interaction $(T \times D)_{i j}$. Errors $e_{i j}$ were assumed to be auto-correlated for repeated observations on the same cow, using a spatial power covariance structure over sampling days (Littell et al., 1998). As the concentrate treatment was only applicable to the treatment period, custom CONTRAST statements were constructed as described by Dieho et al. (2016b) to test for treatment effect and the interaction between treatment and day over the treatment period. Means were separated by formulating CONTRAST or ESTIMATE statements. All results are reported as least squares means with their standard error unless indicated otherwise. Significance of effect was declared at $P$ $\leq 0.05$ and as a trend between $0.05<P \leq 0.10$.

\section{RESULTS}

One cow (RAP) calved early, and missed sampling at $10 \mathrm{~d}$ ap; otherwise, all sampling was completed as planned. Actual sampling days (mean \pm SD) for the pretreatment period were $46.3 \pm 5.1,26.5 \pm 5.7$, and $8.6 \pm 3.4 \mathrm{~d}$ ap, and $3.0 \pm 0.0 \mathrm{~d}$ pp and for the treatment period $9.0 \pm 0.0,16.1 \pm 0.3,30.2 \pm 0.3,44.2 \pm$ $0.4,60.0 \pm 0.9$, and $79.3 \pm 2.2 \mathrm{~d} \mathrm{pp}$.

\section{Feed Intake and Rumen Fluid Composition}

Feed intake and rumen fluid composition have previously been reported in detail by Dieho et al. (2016a). Briefly, DMI approximately doubled from the dry period to $44 \mathrm{~d} \mathrm{pp}$ (Figure 1A) and was neither affected by treatment nor was an interaction observed between treatment and sampling day. Intake of FOM increased 
from $5.6 \mathrm{~kg} / \mathrm{d}$ during the dry period to $14.4 \mathrm{~kg} / \mathrm{d}$ from $44 \mathrm{~d}$ pp onward and was affected by an interaction between treatment and sampling day, with a greater intake for RAP at $16 \mathrm{~d}$ pp compared with GRAD. The abrupt changeover at calving from the dry period ration to the lactation ration resulted in a temporary decrease in NDF intake after calving, whereas intake of CP, starch, and sugar all increased (Figures 1B and 1C). An interaction between treatment and sampling day was observed for CP, starch, and sugar intake, with greater intake of $\mathrm{CP}$, starch, and sugar for RAP compared with GRAD, most notably around $16 \mathrm{~d}$ pp.

The total VFA concentration was affected by sampling day and the treatment and sampling day interaction, but not by treatment (Dieho et al., 2016a). Total rumen fluid VFA concentration increased from approximately $80 \mathrm{~m} M$ during the dry period to $110 \mathrm{~m} M$ during lactation. Rumen fluid $\mathrm{pH}$ was affected by sampling day $(P<0.01)$, decreasing from $\mathrm{pH} 6.72$ during the pretreatment period to 6.17 during the treatment period (Figure 1D), but rumen fluid $\mathrm{pH}$ was not affected by treatment or the interaction between treatment and sampling day $(P \geq 0.24)$. The molar proportion of acetic acid decreased from $73 \%$ during the dry period to $65 \%$ during lactation, whereas the molar proportions of propionic and butyric acid increased from 17 and 10\% during the dry period to 23 and $12 \%$ during lactation, respectively. An interaction between treatment and sampling day was observed for the molar proportions of acetic and propionic acid, but not butyric acid. At 9 and $16 \mathrm{~d}$ pp the molar proportion of propionic acid was higher in RAP (24 and 29\%) compared with GRAD (21 and $23 \%$ ), whereas the molar proportion of acetic acid was lower in RAP (64 and 59\%) compared with GRAD (67 and 65\%) during these days.

\section{Rumen Bacterial Community Composition, and Richness}

Differences in the bacterial community composition were visualized using principal coordinate analysis (Figure 2). Samples taken during the dry period cluster
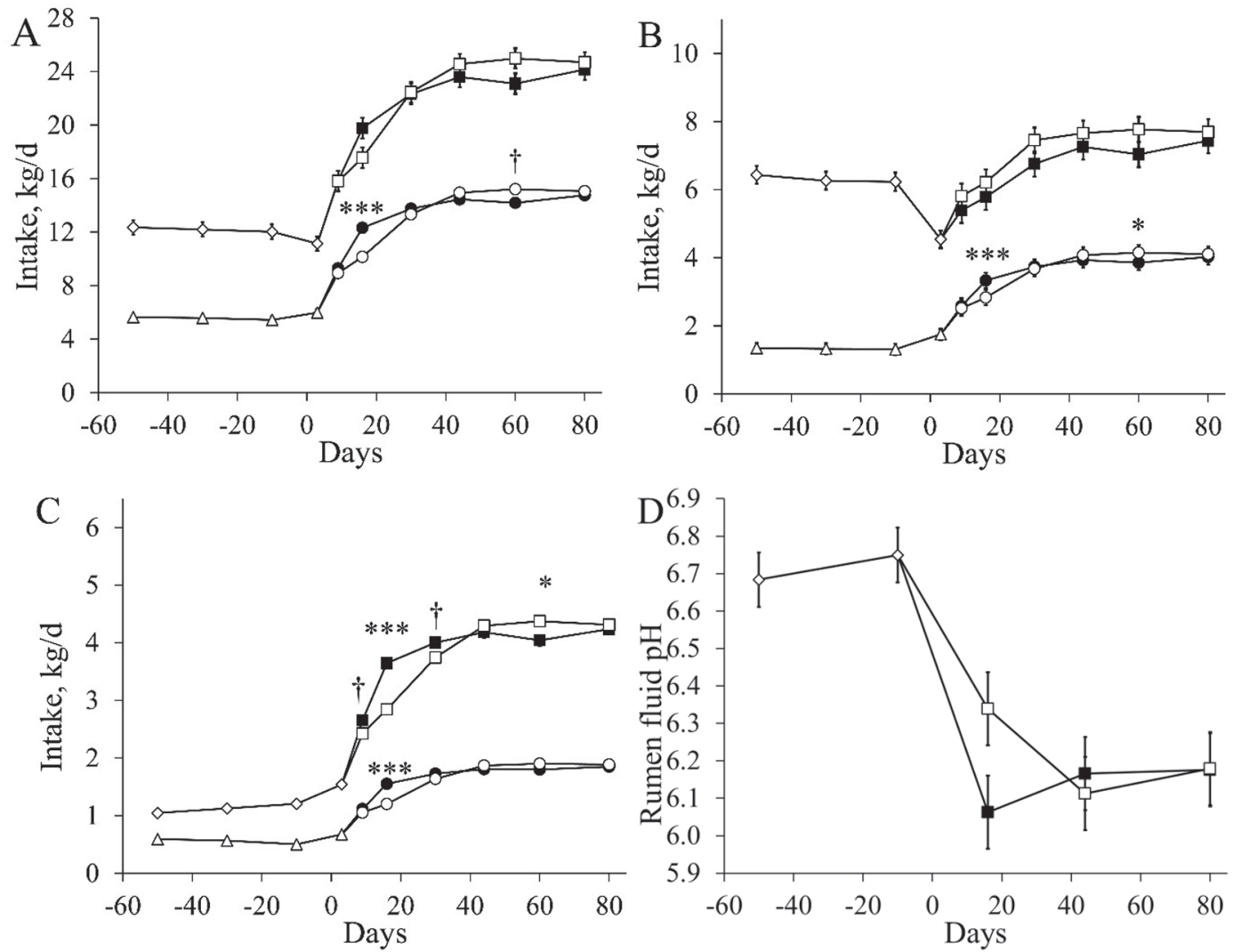

Figure 1. (A) Dry matter $(\diamond \square)$ and fermentable OM $(\Delta \bullet \circ)$ intake, (B) intake of NDF $(\diamond \square \square)$ and CP $(\Delta \bullet \circ)$, (C) intake of starch $(\diamond \square \square)$ and sugar $(\Delta \bullet)$ ), and (D) rumen fluid $\mathrm{pH}(\diamond \square)$ in the pretreatment period $(\diamond \Delta ; \mathrm{n}=12)$ and the treatment period with a rapid $(\mathrm{RAP} ; 1.0 \mathrm{~kg}$ of $\mathrm{DM} / \mathrm{d} ; \boldsymbol{\bullet}, \mathrm{n}=6$ ) or gradual (GRAD; $0.25 \mathrm{~kg}$ of $\mathrm{DM} / \mathrm{d} ; \square \mathrm{O}, \mathrm{n}=6$ ) rate of increase of concentrate allowance postpartum. Values represent $\mathrm{LSM} \pm \mathrm{SE} .{ }^{* * *} P<0.001,{ }^{*} P<0.05, \dagger P<0.10$, significance of difference in LSM of RAP or GRAD. Panels A, B, and C adapted from Dieho et al. (2016a). Panel D adapted from Dieho et al. (2016b). 


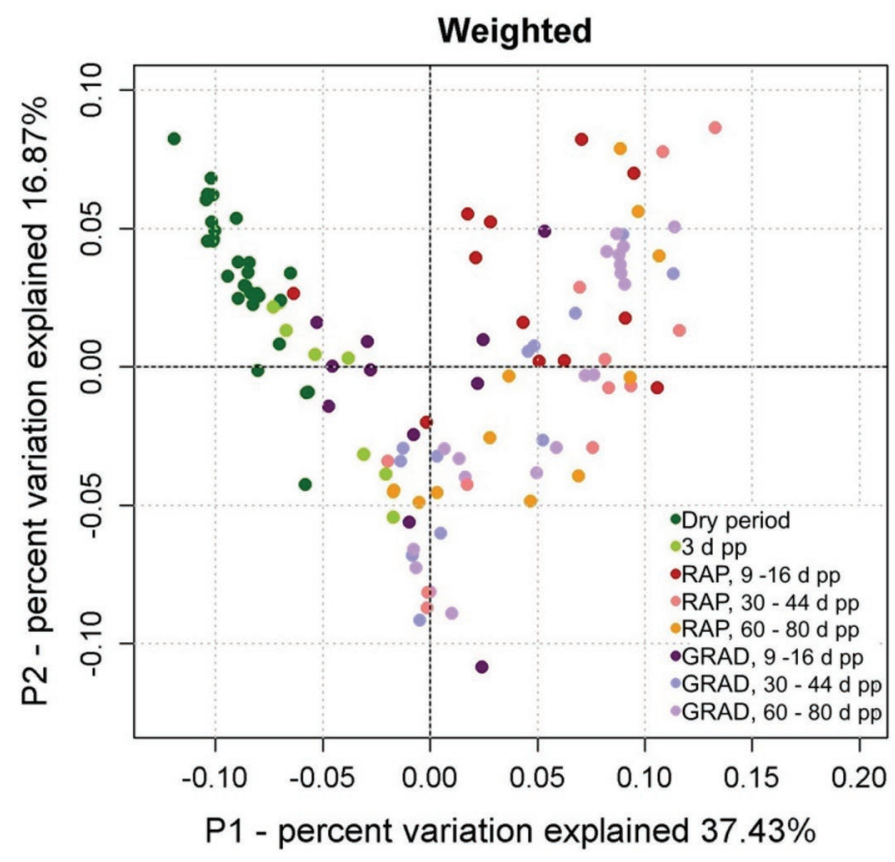

Figure 2. Principal coordinate $(P)$ analysis of the similarity of the bacterial community composition using weighted UniFrac distance metrics during the pretreatment period [50,30, and $10 \mathrm{~d}$ antepartum, and $3 \mathrm{~d}$ postpartum (pp); dark and light green dots, respectively] and the treatment period with a rapid (RAP; $1.0 \mathrm{~kg}$ of DM/d; red/orange dots) or a gradual (GRAD; $0.25 \mathrm{~kg}$ of $\mathrm{DM} / \mathrm{d}$; purple/violet dots) rate of increase of concentrate allowance postpartum. Color version available online.

together, indicating a high degree of similarity, and they were clearly separated from the samples taken during the treatment period. Samples taken $3 \mathrm{~d}$ pp already showed a divergence from dry period samples. Samples taken during the treatment period showed less clear grouping, regardless of sampling day or treatment. Samples from RAP appear to diverge more rapidly from the dry period cluster after the start of the treatment.

The bacterial community richness (Figure 3) decreased over time $(P<0.01)$ and was lower during lactation when compared with the dry period for both RAP and GRAD $(P<0.01)$. During the dry period, community richness of RAP and GRAD was similar. Postpartum, an interaction between sampling day and treatment was observed $(P<0.01)$. Richness was lower for RAP at 9 and $16 \mathrm{~d}$ pp compared with GRAD $(P \leq$ $0.02)$. However, from $30 \mathrm{~d}$ pp onward richness became similar again for RAP and GRAD $(P \geq 0.12)$.

The bacterial community was dominated by orders Clostridiales and Bacteroidales throughout the experiment (Table 1), both comprising a relative abundance of approximately 40\%. The orders Clostridiales, Bacteroidales, Fibrobacterales, Aeromonadales, and Spirochaetales were not affected by treatment or treatment by day interaction. The relative abundance of Clostridiales was generally lower, and that of Bacteroidales generally greater, in the lactation compared with the dry period $(P<0.01)$. The Fibrobacterales comprised $11.4 \%$ of the community during the dry period, but its relative abundance was lower during the lactation $(P$ $<0.01$ ), decreasing to $4.4 \%$ from $44 \mathrm{~d}$ pp onward. In contrast, relative abundance of the Aeromonadales was low $(0.9 \%)$ during the dry period but was higher during the lactation $(P<0.01)$, increasing to $9.0 \%$ from $16 \mathrm{~d}$ pp onward. Only the Erysipelotrichales were affected by treatment $(P=0.03)$, with a relative abundance of $4.2 \%$ in RAP averaged over the treatment period compared with $1.6 \%$ for GRAD. The relative abundance of the Spirochaetales was low throughout the experiment, decreasing from $1.7 \%$ during the dry period to $1.4 \%$ during the lactation $(P<0.01)$. The relative abundance of all other orders of bacteria combined comprised 5.0 and $3.3 \%$ of the community during the pretreatment and treatment periods, respectively.

Of the major taxa at the family and genus level (Table 1), Prevotella had the highest relative abundance during the dry period $(11.6 \%)$ increasing $(P<0.01)$ to $21.8 \%$ during lactation. The RC9 gut group and unclassified Christensenellaceae were prominent community members during the dry period with a relative abundance of 11.6 and $9.5 \%$, respectively. During lactation, however, the relative abundance of these 2 taxa was lower $(P<$ 0.01 ), rapidly decreasing to on average 3.6 and $3.2 \%$

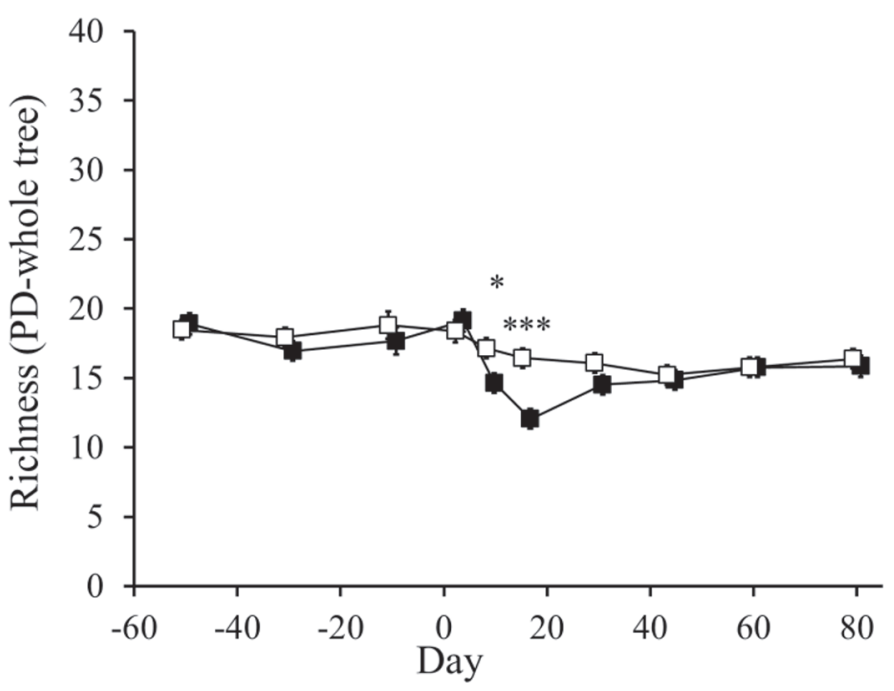

Figure 3. Bacterial community richness $(\square)$ during the pretreatment and treatment periods with a rapid (RAP; $1.0 \mathrm{~kg}$ of DM/d;, $\mathrm{n}$ $=6$ ) or gradual (GRAD; $0.25 \mathrm{~kg}$ of $\mathrm{DM} / \mathrm{d} ; \square, \mathrm{n}=6$ ) rate of increase of concentrate allowance postpartum. Values represent LSM \pm SE. ${ }^{* * *} P<0.001,{ }^{*} P<0.05$, significance of difference in LSM of RAP or GRAD. Values are slightly offset for clarity. $\mathrm{PD}=$ phylogenetic diversity. 
during the lactation period, respectively. Likewise, $\mathrm{Fi}$ brobacter decreased $(P<0.01)$ from $8.4 \%$ during the dry period to $4.7 \%$ during the lactation period. In contrast, the relative abundances of Acetitomaculum and especially the unclassified Succinivibrionaceae increased $(P<0.01)$ from the dry period to the lactation period ( 3.2 to $7.4 \%$ and 0.9 to $7.8 \%$, respectively). The relative abundances of several major taxa were not markedly affected by sampling day, notably Butyrivibrio (8.0\% on average over the experimental period; $P=0.11$ ) and the unclassified Prevotellaceae (4.2\% on average; $P=$ $0.07)$. For 4 out of 22 major taxa, an interaction between treatment and sampling day was observed $(P \leq$ 0.01). The relative abundance of Oribacterium showed a temporary peak for RAP at $16 \mathrm{~d}$ pp compared with GRAD, whereas the relative abundances of the unclassified Ruminococcaceae, Saccharofermentans, and Xylanibacter were lower in RAP compared with GRAD at $16 \mathrm{~d}$ pp. The unclassified Erysipelotrichaceae tended to be affected by treatment only, with numerically higher relative abundances in RAP during the treatment period $(3.6 \%$ average) compared with GRAD (1.5\%).

\section{Rumen Protozoal and Archaeal Community Composition}

Rumen protozoal communities were more diverse during the dry period (10 d ap) compared with the lactation period (16 and $44 \mathrm{~d}$ pp; Figure 4). Epidinium and Ostracodinium were the dominant protozoal genera during the dry period with a relative abundance of 40.7 and $21.9 \%$, respectively. The relative abundances of Eudiplodinium (11.0\%), Anaplodinium-Diplodinium (9.7\%), and the holotrich Isotricha-Dasytricha (8.3\%) were similar to each other at $10 \mathrm{~d}$ ap. During lactation the relative abundance of Epidinium increased $(P$ $<0.01$ ), dominating the protozoal community with an average relative abundance of $68.5 \%$ at $44 \mathrm{~d}$ pp. Likewise, Entodinium increased relative to the dry period $(P<0.01)$ to $16.3 \%$ at $44 \mathrm{~d}$ pp. In contrast, Ostracodinium, Eudiplodinium, Anaplodinium-Diplodinium, and Eremoplastron-Diploplastron all decreased $(P<0.01)$ during lactation to relative abundancies between 1.4 to $3.3 \%$ at $44 \mathrm{~d}$ pp. An interaction between sampling day and treatment was observed for several protozoal genera. The relative abundance of Ostracodinium, Eudiplodinium, Anaplodinium-Diplodinium, EremoplastronDiploplastron, and Metadinium-Polyplastron at $16 \mathrm{~d} \mathrm{pp}$ was lower in RAP compared with GRAD. In contrast, the relative abundance of Entodinium was greater in RAP than GRAD by $16 \mathrm{~d}$ pp. By $44 \mathrm{~d}$ pp no more differences were found in the relative abundance of the protozoal community members between treatments.
The relative abundance of the Methanobrevibacter gottschalkii (57.8\%) and Methanobrevibacter ruminantium $(29.8 \%)$ clades dominated the archaeal community at $10 \mathrm{~d}$ ap (Figure 4). In contrast to the relative abundance of $M b b$. ruminantium, which did not change throughout the experiment $(P=0.63)$, that of $M b b$. gottschalkii decreased during the lactation $(P<0.01)$ in particular with RAP for which an interaction $(P$ $=0.02$ ) between sampling day and treatment was observed. The relative abundances of Methanomassiliicoccaceae and Methanosphaera increased $(P<0.01)$ from 7.8 and $2.8 \%$ at $10 \mathrm{~d}$ ap to 19.5 and $11.0 \%$ at $44 \mathrm{~d}$ $\mathrm{pp}$, respectively. For all of these taxa, an interaction between treatment and sampling day was observed $(P$ $\leq 0.04$ ). During the dry period no differences were observed between the treatment groups. At $16 \mathrm{~d}$ pp, the relative abundance of $M b b$. gottschalkii was lower, and that of Mbb. ruminantium, Methanomassiliicoccaceae, and Methanosphaera was higher with RAP than GRAD. By $44 \mathrm{~d}$ pp differences between RAP and GRAD were only observed for Mbb. gottschalkii and ruminantium.

\section{In Situ Fractional Degradation Rate}

The fractional degradation rates of starch, NDF, CP, and OM (Table 2) were neither affected by starting day of the in situ incubation $(P \geq 0.18)$ nor by treatment $(P \geq 0.24)$, and no interaction was observed between both factors $(P \geq 0.12)$. The $k_{\mathrm{d}}$ of starch tended to be higher during lactation compared with the dry period $(P=0.07)$. A similar numerical change is suggested by the $k_{\mathrm{d}}$ of $\mathrm{CP}(P=0.12)$, whereas no such change is suggested by the $k_{\mathrm{d}}$ of NDF and OM.

\section{DISCUSSION}

\section{Ration Effects on Bacterial Community Richness}

Richness of the bacterial community is known to fluctuate throughout the lactation cycle (Jewell et al., 2015), and older cows have been reported to host a richer and more diverse microbiota than heifers (Lima et al., 2015). The first weeks after calving coincide with a large increase in DMI and in increase in dietary FOM content, which is typically achieved by an inclusion of grains or pelleted concentrates in the ration. By comparing the bacterial community at $7 \mathrm{~d}$ ap and $7 \mathrm{~d}$ pp, Lima et al. (2015) showed that richness and diversity decreased after calving, both in primiparous and multiparous cows. However, Wang et al. (2012) did not observe changes in richness and diversity during the transition period in samples taken at weekly intervals from $21 \mathrm{~d}$ ap to $21 \mathrm{~d}$ pp. In the present study, we 


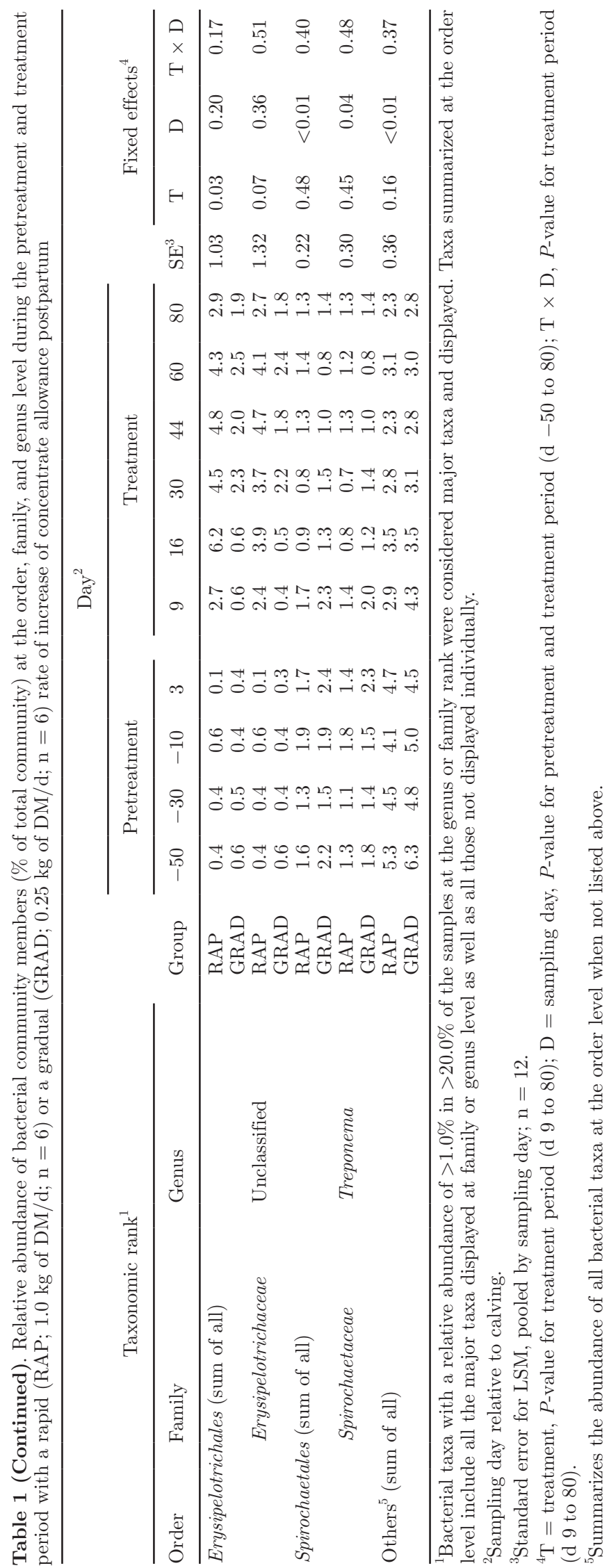

observed a sharp but temporary decrease in richness early postpartum with the rapid increase in concentrate allowance. Similar to Lima et al. (2015), this change in composition occurred rapidly, indicating little time is required for bacterial community adaption to manifest. Although the decrease in richness was much less pronounced with a gradual increase in concentrate allowance, the richness during lactation was still lower compared with the richness in the dry period.

The decrease in richness with a rapid increase in concentrate allowance (RAP) was not associated with an overgrowth of the rumen bacterial community by a small number of taxa as evidenced by the relative abundances of the major bacterial taxa. This suggests that a range of bacterial taxa can capitalize on the rapid increase in readily fermentable OM, thereby reducing the relative abundance of other taxa below the detection limit. With a gradual increase in concentrate allowance (GRAD), changes were more gradual especially after 9 d pp, allowing the minor species to maintain their presence at detectable levels. The recovery in richness might then be explained by the cessation of rapid concentrate build-up after $16 \mathrm{~d} \mathrm{pp}$, which might have removed the competitive advantage.

Simultaneous with the increase in readily fermentable OM, changes in the rumen fluid might further affect the relative abundance of taxa, both positively and negatively. As reported by Dieho et al. (2016b), the greater intake of FOM, starch, and sugar in RAP compared with GRAD at $16 \mathrm{~d}$ pp increased daily VFA production, particularly production of propionic acid, and resulted in a decrease in $\mathrm{pH}$, especially the time rumen fluid $\mathrm{pH}$ was below 5.8. At $44 \mathrm{~d} \mathrm{pp}$, average rumen fluid $\mathrm{pH}$ was similar for RAP and GRAD, and also the time rumen fluid $\mathrm{pH}$ was below 5.8 did not differ. This suggests that cows in RAP had the capacity to limit further decreases in $\mathrm{pH}$, which might also be advantageous in the recovery of bacterial richness.

Alternatively, it can be hypothesized that the driving force behind the differences in richness between RAP and GRAD at 9 and $16 \mathrm{~d} p \mathrm{pp}$ is the difference in daily FOM intake, in particular that of starch and sugar intake, rather than the actual amount of FOM consumed. If the absolute level of FOM, starch, and sugar intake drives the decrease in richness, a continued decreased richness would be expected for RAP after $16 \mathrm{~d}$ pp. In addition, a gradual decrease in richness for GRAD at d 44 to the same reduced level of bacterial richness as in RAP at d 16 should be observed, as intake of the rapidly fermentable OM at d 44 in GRAD is equal to that at d 16 in RAP. However, such decreases in richness were not observed. Richness actually recovered after $16 \mathrm{~d}$ pp in RAP and only a small decline in richness in GRAD up to d 44 occurred. Therefore it can be 

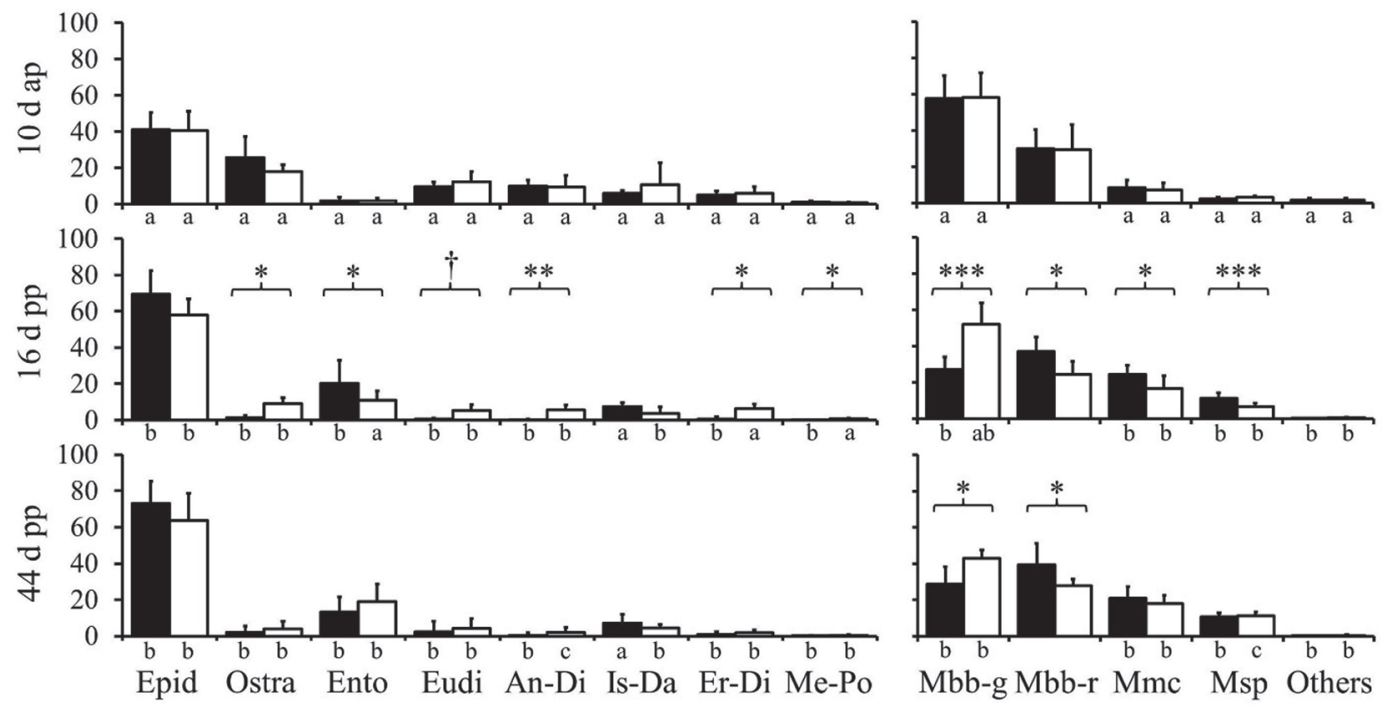

Figure 4. Least squares means of relative abundance of rumen protozoal (left chart) and archaeal (right chart) community members expressed as a fraction (\%) of the total community during the pretreatment period (10 d antepartum; ap) and the treatment period (16 and $44 \mathrm{~d}$ postpartum; pp) with a rapid (RAP; $1.0 \mathrm{~kg}$ of DM/d; black bars) or gradual (GRAD; $0.25 \mathrm{~kg}$ of DM/d; white bars) rate of increase of concentrate allowance postpartum. Epid, Epidinium; Ostra, Ostracodinium; Ento, Entodinium spp.; Eudi, Eudiplodinium; An-Di, AnaplodiniumDiplodinium; Is-Da, Isotricha-Dasytricha; Er-Di, Eremoplastron-Diploplastron; Me-Po, Metadinium-Polyplastron; Mbb-g, Methanobrevibacter gottschalkii clade; Mbb-r, Methanobrevibacter ruminantium clade; Mmc, Methanomassiliicoccaceae; Msp, Methanosphaera: Others, sum of remaining archaeal taxa. $\dagger P<0.10,{ }^{*} P<0.05,{ }^{* *} P<0.01$, ${ }^{* * *} P<0.001$, significance of difference in LSM of RAP or GRAD for the same sampling day and taxon. ${ }^{\text {a-c }}$ Indicates differences between days within treatment group, $P \leq 0.05$. Error bars represent SD.

Table 2. Fractional degradation rate $\left(k_{\mathrm{d}}\right)$ of starch, NDF, CP, and OM determined with nylon bag incubations of soybean hulls and corn, during the pretreatment ( $-14 \mathrm{~d}$ relative to calving) and treatment period $(18,46$, and $62 \mathrm{~d}$ relative to calving) with a rapid (RAP; $1.0 \mathrm{~kg}$ of $\mathrm{DM} / \mathrm{d} ; \mathrm{n}=3$ ) or a gradual (GRAD; $0.25 \mathrm{~kg}$ of $\mathrm{DM} / \mathrm{d} ; \mathrm{n}=3$ ) rate of increase of concentrate allowance postpartum

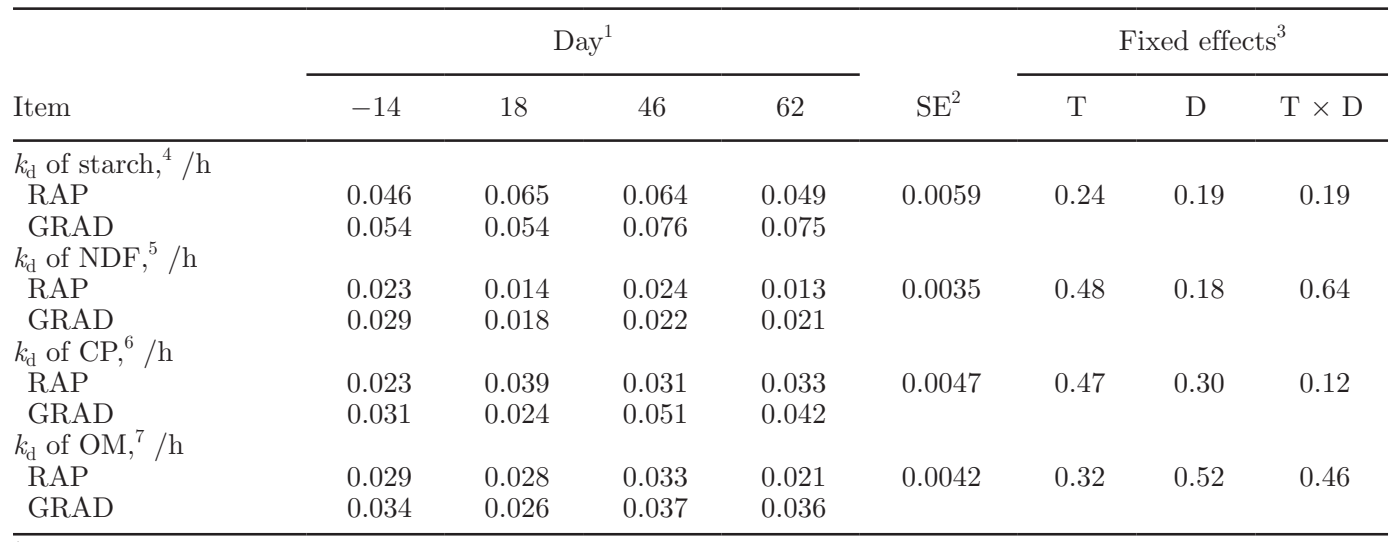

${ }^{1}$ Day of start of incubation.

${ }^{2}$ Standard error for LSM, pooled by sampling day; $\mathrm{n}=6$.

${ }^{3} \mathrm{~T}=$ treatment, $P$-value for treatment period (d 18 to 62$) ; \mathrm{D}=$ day of start of incubation, $P$-value for pretreatment and treatment period $(\mathrm{d}-14$ to 62$) ; \mathrm{T} \times \mathrm{D}, P$-value for treatment periods (d 18 to 62$)$.

${ }^{4}$ Starch: washout (W)-fraction, $0.25 \pm 0.010$.

${ }^{5} \mathrm{NDF}$ : lag, $2.4 \pm 1.13 \mathrm{~h}$; undegradable (U)-fraction; $0.03 \pm 0.003$.

${ }^{6} \mathrm{CP}$ : W-fraction, $0.19 \pm 0.011$; U-fraction, $0.05 \pm 0.037$.

${ }^{7} \mathrm{OM}$ : W-fraction, $0.16 \pm 0.010 ; \mathrm{U}$-fraction, $0.02 \pm 0.006$. 
suggested that a rapid (in several days only) increase of intake of readily fermentable OM to a level above a certain threshold, and not the daily intake level as such, is required to decrease bacterial richness.

\section{Ration Effects on the Relative Abundance of Bacterial Community Members}

With a few exceptions discussed in more detail below, most of the major taxa only showed rather low association scores $(-0.45<$ association $<0.45)$ between their relative abundance and measures of daily feed intake, ration composition, and rumen fluid composition, indicating limited effects of DMI and ration composition
(Figure 5). The genera Acetitomaculum and Prevotella showed a strong positive association with DMI and the fractions of FOM, starch, sugar, and $\mathrm{CP}$ in the rations, reflecting the increase in their relative abundance after calving. As shown by Dieho et al. (2016b), treatment RAP resulted in a temporary peak in the production rate of propionate. This was reflected by a higher molar proportion and concentration of propionate in the rumen fluid. In turn, this has a strong positive association with the abundance of Prevotella, unclassified Succinivibrionaceae, and Oribacterium, which are known producers of propionate (Stewart et al., 1997). In contrast, the RC9 gut group, unclassified Christensenellaceae, and to lesser degree Fibrobacter and other unclassified

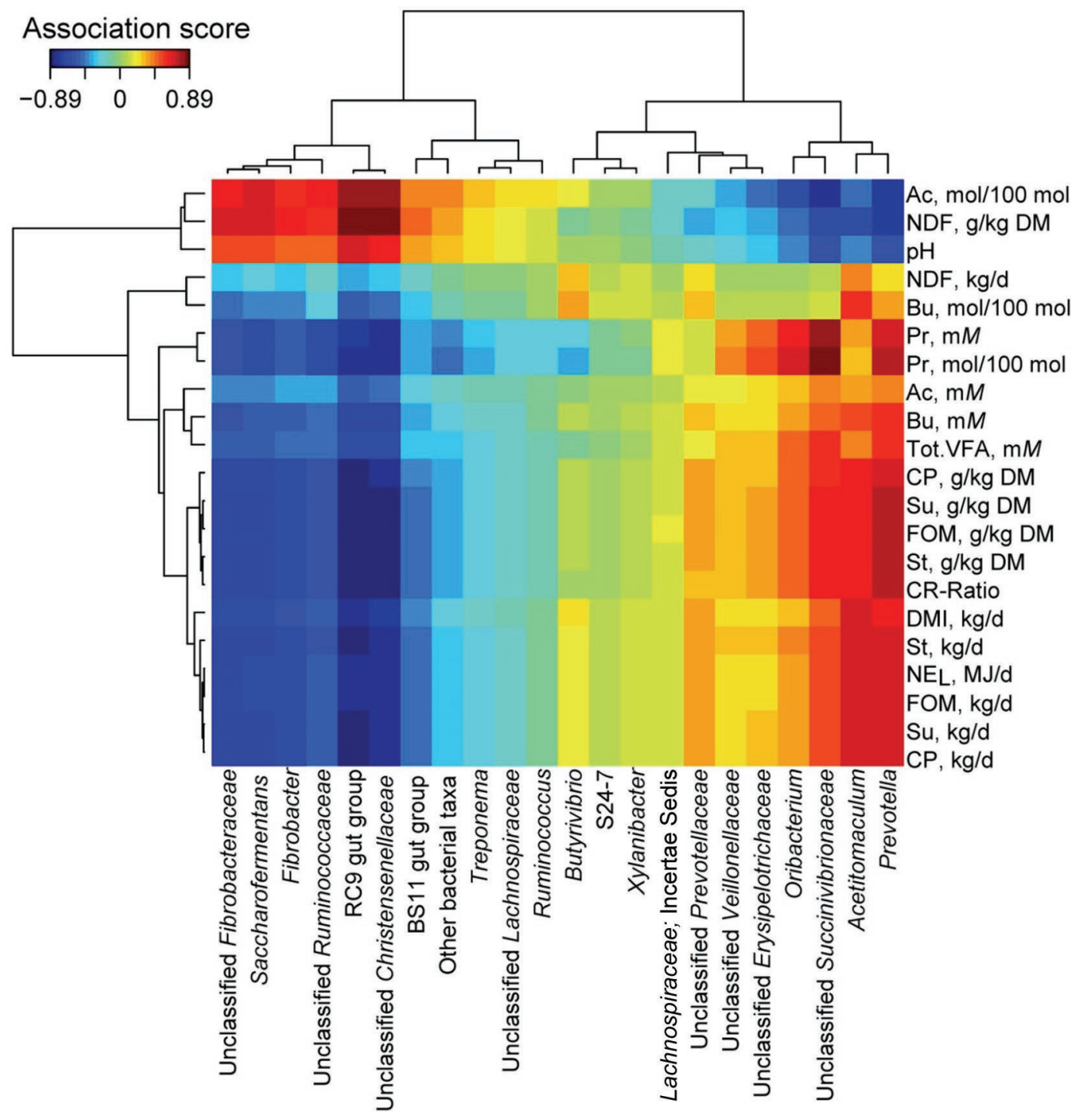

Figure 5. Heatmap of the associations between bacterial community composition and rumen fluid composition and feed intake variables using regularized canonical correlation analysis. Ac, acetic acid; Bu, butyric acid; Pr, propionic acid; Tot., total; Su, sugar; FOM, fermentable organic matter; St, starch; CR-Ratio, concentrate to roughage ratio. Color version available online. 
Fibrobacteraceae, unclassified Ruminococcaceae, and Saccharofermentans showed a strong positive association with the fraction of NDF in the ration, reflecting their higher relative abundance during the dry period. Fibrobacter and the Ruminococcaceae are known cellulose degraders and the abundance of substrate, fibrous quality of the feed, low fractional passage rates, and higher ruminal $\mathrm{pH}$ likely all favor their presence during the dry period (Stewart et al., 1997; Ransom-Jones et al., 2012). This also explains their strong positive association with the molar proportion of acetate and negative association with the molar proportion of propionate. Despite their abundance, little is known about the RC9 gut group or the Rikenellaceae and their function is unclear, warranting further exploration of these taxa.

In comparison to some studies, where bacterial communities were dominated by Bacteroidales, and specifically its genus Prevotella (Jami et al., 2013; Pitta et al., 2014), in the present study multiple orders of bacteria have a sizable relative abundance. Such more diverse bacterial communities appear to be more common globally (Henderson et al., 2015), and is likewise reported by Wang et al. (2012), Petri et al. (2013), and Lima et al. (2015). This diversity might be explained by the composition of the concentrate, containing equal levels of starch and NDF (both some $250 \mathrm{~g} / \mathrm{kg}$ of DM). Concentrates containing large amounts of grains are commonly fed, providing more starch per kilogram of DM. Such rations typically increase the relative abundance of Prevotella (Pitta et al., 2014). Nevertheless, Prevotella also had the highest relative abundance during lactation in the present study, as is typically observed.

It has been demonstrated that the DNA extraction technique used affects the observations on the microbiota community (Henderson et al., 2013). For the present experiment, the extraction kit used yields high-quality DNA (Zoetendal et al., 2006; Henderson et al., 2013; van den Bogert et al., 2013). Moreover, the DNA extraction protocol included a mechanical lysis step and a phenol-chloroform extraction step, increasing DNA yield (Henderson et al., 2013). Although comparing microbiota communities observed using different protocols should be done with care, results from experiments that include a mechanical lysis step and a phenol-chloroform extraction step tend to allow for better comparison (Henderson et al., 2013).

Despite the clear effect of the concentrate treatment on the richness of the rumen bacterial community, at order level only the relative abundance of Erysipelotrichales was affected by concentrate treatment. Similarly, at family and genus level the relative abundance of only a few of the major taxa was affected by the interaction between sampling day and treatment. This contrasts with the effect of the ration changes associated with transition from the dry period to lactation on the relative abundance of these taxa. Due to the similarity of a large part of the rumen bacterial community in RAP and GRAD, differences in capacity for degradation are also likely limited. Indeed, no effect of treatment or of period by treatment interaction on fractional degradation rates of several substrates was observed. The rapid changes in relative abundance of Prevotella, the RC9 gut group, and unclassified Christensenellaceae with onset of feeding the lactation ration suggest that the bacterial community can adapt quickly.

\section{Changes in Rumen Protozoal and Archaeal Communities}

The dominance of Epidinium during lactation is unusual, as often Entodinium is found to be most abundant in both forage and concentrate dominated rations (Hristov et al., 2001; Henderson et al., 2015). Whereas both genera have similar growth rates in vitro (Dehority, 2003), their respective capacities for degradation of substrates differ. Members of Entodinium are known to be able to rapidly engulf starch particles (Williams and Coleman, 1992). The increase in their relative abundance after calving, and higher abundance in RAP at $16 \mathrm{~d} p p$, likely reflects their capacity to capitalize on the increased fractions of starch in the rations. Epidinium likewise engulfs starch, albeit more slowly than Entodinium (Williams and Coleman, 1992), but in contrast to Entodinium, Epidinium has a high cellulase activity and actively invades plant tissues. In addition, Epidinium degrades pectins, hemicelluloses, and xylans (nonstarch polysaccharides) faster than Entodinium (Williams and Coleman, 1992). Several of the concentrate ingredients (citrus pulp, sugar beet pulp) contain a substantial amount of nonstarch polysaccharides (and a relatively small amount of NDF). Epidinium can capitalize on the postpartum increase in the fractions of starch, pectins, hemicelluloses, and xylans, explaining its increase despite the decrease in the fraction of cellulose. However, the lower rumen fluid $\mathrm{pH}$ coinciding with RAP (Dieho et al., 2016b), which likely negatively affects Epidinium more than Entodinium (Williams and Coleman, 1992), might explain the lack of a treatment effect at $16 \mathrm{~d}$ pp. The capacity of Epidinium to invade plant tissue might partly explain the overall relatively high abundance of Epidinium as both rumen fluid and feed particles were sampled in the present study. A major part of the samples collected by Henderson et al. (2015) likewise consisted of 
whole rumen contents, but they did not observe most Epidinium in the protozoal community. The relatively high abundance of Ostracodinium as observed during the dry period with forage dominated rations, and low relative abundance in concentrate dominated rations corresponds with earlier reports (Hristov et al., 2001; Henderson et al., 2015). Like Epidinium, Ostracodinium has a large capacity to degrade cellulose, explaining its relatively high abundance during the dry period where there was an abundance of substrate and a relatively high rumen fluid $\mathrm{pH}$, and similarly explains the significantly higher abundance at $16 \mathrm{pp}$ with RAP compared with GRAD. The near disappearance of Ostracodinium after calving, in particular at d $44 \mathrm{pp}$, can be associated with the increase in fermentation rate of the ration and the concomitant decrease in $\mathrm{pH}$ (Goad et al., 1998; Hristov et al., 2001).

In line with previous studies (e.g., Henderson et al., 2015), in the present study rumen archaea were found to be much less diverse than rumen bacteria. This likely reflects the narrow range of substrates they use. The dominance of the hydrogen utilizers Mbb. gottschalkii and $M b b$. ruminantium clades within the archaeal community is commonly observed (Janssen and Kirs, 2008; Henderson et al., 2015). The decrease in the relative abundance of $M b b$. gottschalkii likely represents a greater sensitivity to the changes in feed intake and rumen environment ( $\mathrm{pH}, \mathrm{H}_{2}$ concentration), particularly in RAP up to $16 \mathrm{~d}$ pp. However, after having reached the maximum concentrate allowance, ration changes in RAP were minimal, and differences in rumen fluid VFA concentration and $\mathrm{pH}$ between RAP and GRAD disappeared. This suggest that the selective pressure on both clades might be similar from $16 \mathrm{~d}$ pp onward, resulting in an apparent persistence of the treatment effect. The postpartum increase in methylotrophic Methanomassiliicoccaceae and treatment effect at $16 \mathrm{~d}$ pp is likely the result of the concentrate intake during lactation. These archaea metabolize methylamines (Poulsen et al., 2013), which increase in concentration with an increased intake of grains (Ametaj et al., 2010).

\section{Functional Changes in the Rumen Microbiota}

From a rumen function perspective, it is important to evaluate whether the loss of richness and changes in the relative abundance of individual taxa during the first weeks of lactation also affected the degradation of rumen substrates. The concept of a functional redundant rumen microbiome (Weimer, 2015), together with the present observation of a continuous sizable relative abundance of many of the major bacterial taxa, suggests that the microbiota community had a continuous capacity to degrade a wide range of substrates throughout the whole experimental period. Predicting the degradation capacity of a microbiota community based on its composition remains difficult as the metabolic capabilities have not been assessed in culture for most of the microbiota (Creevey et al., 2014). Therefore, in situ incubations were used to assess the degradation capacity in the present study. The effect of the rumen evacuations on the in situ incubations was likely limited as $\sim 48 \mathrm{~h}$ (lactation period) or $\sim 2 \mathrm{wk}$ (dry period) separated the return of the rumen contents and the start of incubation. In addition, the all-out method was chosen as this minimizes the possible effect of rumen evacuation on the in situ incubations. The longest incubation times $(72$ and $48 \mathrm{~h}$ ) were closest to the moment of evacuation, whereas the shorter incubation times $(<24$ h), which have more of an effect on the shape of the degradation curve, and hence the $k_{\mathrm{d}}$, were added last and thus farther from the moment of evacuation. In addition, rumen evacuations are reported to have limited effects on rumen functioning (Towne et al., 1986) and no adverse effects of the rumen evacuation on feed intake and milk production were observed (Dieho et al., 2016a), also suggesting unaltered rumen function.

Ground corn and soybean hulls were used as substrate for in situ incubations for their high starch and NDF contents, respectively. However, CP content was low in both substrates (97 and $118 \mathrm{~g} / \mathrm{kg}$ of DM, respectively). Consequently, the relatively small amounts of substrate incubated might have been affected by contamination with microbial protein (Vanzant et al., 1998). The fractional degradation rates observed for $\mathrm{CP}$ should therefore be treated with caution. The fractional degradation rates of starch are comparable to the $5.5 \% / \mathrm{h}$ for ground corn reported by Offner et al. (2003). The wash-out fraction was somewhat smaller than that observed by Offner et al. (2003), but differences in sample processing (screen size used for grinding) and washing technique are likely factors that may explain this difference (Vanzant et al., 1998).

The digestion of NDF has been shown to be reduced at lower $\mathrm{pH}$ values (Calsamiglia et al., 2008). Likewise, the rate of degradation was found to be lower at a higher concentrate inclusion rate, which coincided with a lower $\mathrm{pH}$ (Stensig and Robinson, 1997). The numerically lower NDF degradation rate at $18 \mathrm{~d}$ pp compared with the dry period may reflect an effect of the reduced rumen $\mathrm{pH}$ in RAP in the present study (numerically lower at $16 \mathrm{~d}$ pp, Figure 1D). Rumen fluid $\mathrm{pH}$ was reduced below $\mathrm{pH} 5.8$ for a larger fraction of time in RAP than GRAD (Dieho et al., 2016b), suggesting a degree of SARA occurred in RAP. However, the lack of a clear lactation or treatment effect on the fractional 
degradation rate of OM, NDF, and starch in the nylon bags suggests that functionally the microbiota communities did not differ throughout the whole experiment. This might indicate that the composition of the microbiota of lactating cows on high-concentrate ration (approximately 60\%) enables it to degrade the selected substrates in a lower $\mathrm{pH}$ and higher VFA concentration environment in vivo at a similar rate as cows on a forage-dominated ration during the dry period with a high $\mathrm{pH}$ and low VFA concentration environment. Alternatively, the variation in in situ incubation results may have been too large to establish a treatment or lactation stage effect. Overall, in the present experiment the loss in bacterial richness and the changes in relative abundance of individual taxa in response to dietary changes were not associated with changes in rumen degradation kinetics.

\section{CONCLUSIONS}

Richness of the rumen bacterial community decreased during the transition from the dry period to lactation. Furthermore, a rapid increase in concentrate allowance temporarily decreased richness of the bacterial community compared with a gradual increase to the same maximum daily concentrate allowance. Principal coordinate analysis and changes in the relative abundances of bacterial taxa show that adaptation of the community composition to changes in the ration occurs rapidly. The relative abundances of most major bacterial taxa were affected by the transition to lactation, but few were affected by the rate of increase of the concentrate allowance. The relative abundances of rumen protozoal taxa changed after calving and were affected by the concentrate treatment. However, differences between treatments groups disappeared again when concentrate intake became similar. The archaeal community was likewise affected by both the transition to lactation and the treatment. The observed changes in rumen microbiota composition including changes in bacterial community richness did not appear to affect the fractional degradation rate of NDF, starch, $\mathrm{CP}$, and OM measured in situ using a nylon bag technique.

\section{ACKNOWLEDGMENTS}

The authors acknowledge the Dairy Campus staff (Lelystad, the Netherlands) for their technical support, Arie Klop (Wageningen, the Netherlands) for his assistance with the in situ incubations, and Faith Cox and Peter Janssen (AgResearch Ltd., Hamilton, New Zealand) for accepting and processing our samples as part of the Global Rumen Census. The authors ac- knowledge the financial support of the Product Board Animal Feed (Zoetermeer, the Netherlands) and Dutch Dairy Board (Zoetermeer, the Netherlands).

\section{REFERENCES}

Altschul, S. F., W. Gish, W. Miller, E. W. Myers, and D. J. Lipman. 1990. Basic local alignment search tool. J. Mol. Biol. 215:403-410. https://doi.org/10.1016/S0022-2836(05)80360-2.

Ametaj, B. N., Q. Zebeli, F. Saleem, N. Psychogios, M. J. Lewis, S. M. Dunn, J. Xia, and D. S. Wishart. 2010. Metabolomics reveals unhealthy alterations in rumen metabolism with increased proportion of cereal grain in the diet of dairy cows. Metabolomics 6:583-594. https://doi.org/10.1007/s11306-010-0227-6.

Belanche, A., M. Doreau, J. E. Edwards, J. M. Moorby, E. Pinloche, and C. J. Newbold. 2012. Shifts in the rumen microbiota due to the type of carbohydrate and level of protein ingested by dairy cattle are associated with changes in rumen fermentation. J. Nutr. 142:1684-1692. https://doi.org/10.3945/jn.112.159574.

Bergman, E. N. 1990. Energy contributions of volatile fatty acids from the gastrointestinal tract in various species. Physiol. Rev. 70:567-590.

Berry, D., K. Ben Mahfoudh, M. Wagner, and A. Loy. 2011. Barcoded primers used in multiplex amplicon pyrosequencing bias amplification. Appl. Environ. Microbiol. 77:7846-7849. https://doi. org/10.1128/AEM.05220-11.

Calsamiglia, S., P. W. Cardozo, A. Ferret, and A. Bach. 2008. Changes in rumen microbial fermentation are due to a combined effect of type of diet and pH. J. Anim. Sci. 86:702-711. https://doi org/10.2527/jas.2007-0146.

Caporaso, J. G., J. Kuczynski, J. Stombaugh, K. Bittinger, F. D. Bushman, E. K. Costello, N. Fierer, A. G. Pena, J. K. Goodrich, J. I. Gordon, G. A. Huttley, S. T. Kelley, D. Knights, J. E. Koenig, R. E. Ley, C. A. Lozupone, D. McDonald, B. D. Muegge, M. Pirrung, J. Reeder, J. R. Sevinsky, P. J. Turnbaugh, W. A. Walters, J. Widmann, T. Yatsunenko, J. Zaneveld, and R. Knight. 2010. QIIME allows analysis of high-throughput community sequencing data. Nat. Methods 7:335-336. https://doi.org/10.1038/ nmeth.f.303.

Creevey, C. J., W. J. Kelly, G. Henderson, and S. C. Leahy. 2014. Determining the culturability of the rumen bacterial microbiome. Microb. Biotechnol. 7:467-479. https://doi.org/10.1111/17517915.12141.

Dehority, B. A. 2003. Rumen Microbiology. Nottingham University Press, Nottingham, UK.

Dieho, K., A. Bannink, I. A. L. Geurts, J. T. Schonewille, G. Gort, and J. Dijkstra. 2016a. Morphological adaptation of rumen papillae during the dry period and early lactation as affected by rate of increase of concentrate allowance. J. Dairy Sci. 99:2339-2352. https://doi.org/10.3168/jds.2015-9837.

Dieho, K., J. Dijkstra, J. T. Schonewille, and A. Bannink. 2016b. Changes in ruminal volatile fatty acid production and absorption rate during the dry period and early lactation as affected by rate of increase of concentrate allowance. J. Dairy Sci. 99:5370-5384. https://doi.org/10.3168/jds.2015-10819.

Edwards, J. E., N. R. McEwan, A. J. Travis, and R. John Wallace. 2004. 16S rDNA library-based analysis of ruminal bacterial diversity. Antonie van Leeuwenhoek 86:263-281. https://doi. org/10.1023/B:ANTO.0000047942.69033.24.

Faith, D. P. 1992. Conservation evaluation and phylogenetic diversity. Biol. Conserv. 61:1-10.

Fernando, S. C., H. T. Purvis, F. Z. Najar, L. O. Sukharnikov, C. R. Krehbiel, T. G. Nagaraja, B. A. Roe, and U. DeSilva. 2010. Rumen microbial population dynamics during adaptation to a highgrain diet. Appl. Environ. Microbiol. 76:7482-7490. https://doi. org/10.1128/AEM.00388-10.

Goad, D. W., C. L. Goad, and T. G. Nagaraja. 1998. Ruminal microbial and fermentative changes associated with experimentally induced subacute acidosis in steers. J. Anim. Sci. 76:234-241. 
González, I., K.-A. Lê Cao, M. J. Davis, and S. Déjean. 2012. Visualising associations between paired 'omics' data sets. BioData Min. 5:19. https://doi.org/10.1186/1756-0381-5-19.

Henderson, G., F. Cox, S. Ganesh, A. Jonker, W. Young, Global Rumen Census Collaborators, and P. H. Janssen. 2015. Rumen microbial community composition varies with diet and host, but a core microbiome is found across a wide geographical range. Sci. Rep. 5:14567. https://doi.org/10.1038/srep14567.

Henderson, G., F. Cox, S. Kittelmann, V. H. Miri, M. Zethof, S. J. Noel, G. C. Waghorn, and P. H. Janssen. 2013. Effect of DNA extraction methods and sampling techniques on the apparent structure of cow and sheep rumen microbial communities. PLoS One 8:e74787. https://doi.org/10.1371/journal.pone.0074787.

Hristov, A. N., M. Ivan, L. M. Rode, and T. A. McAllister. 2001. Fermentation characteristics and ruminal ciliate protozoal populations in cattle fed medium- or high-concentrate barley-based diets. J. Anim. Sci. 79:515-524. 2001.792515x.

ISO. 1999. Animal feeding stuffs - Determination of moisture and other volatile matter content. ISO 6496. International Organization for Standardization (ISO). Geneva, Switzerland.

ISO. 2002. Animal feeding stuffs - Determination of crude ash. ISO 5984. International Organization for Standardization, Geneva, Switzerland.

ISO. 2004. Animal feeding stuffs-Enzymatic determination of total starch content. International Organization for Standardization, Geneva, Switzerland.

ISO. 2005. Animal feeding stuffs - Determination of nitrogen content and calculation of crude protein content-Part 1: Kjeldahl method. ISO 5983-1. International Organization for Standardization, Geneva, Switzerland.

Jami, E., A. Israel, A. Kotser, and I. Mizrahi. 2013. Exploring the bovine rumen bacterial community from birth to adulthood. ISME J. 7:1069-1079. https://doi.org/10.1038/ismej.2013.2.

Janssen, P. H., and M. Kirs. 2008. Structure of the archaeal community of the rumen. Appl. Environ. Microbiol. 74:3619-3625. https:// doi.org/10.1128/AEM.02812-07.

Jewell, K. A., C. A. McCormick, C. L. Odt, P. J. Weimer, and G. Suen. 2015. Ruminal bacterial community composition in dairy cows is dynamic over the course of two lactations and correlates with feed efficiency. Appl. Environ. Microbiol. 81:4697-4710. https://doi. org/10.1128/AEM.00720-15.

Kim, M., M. Morrison, and Z. Yu. 2011. Status of the phylogenetic diversity census of ruminal microbiomes. FEMS Microbiol. Ecol. 76:49-63. https://doi.org/10.1111/j.1574-6941.2010.01029.x.

Kittelmann, S., and P. H. Janssen. 2011. Characterization of rumen ciliate community composition in domestic sheep, deer, and cattle, feeding on varying diets, by means of PCR-DGGE and clone libraries. FEMS Microbiol. Ecol. 75:468-481. https://doi. org/10.1111/j.1574-6941.2010.01022.x.

Lima, F. S., G. Oikonomou, S. F. Lima, M. L. S. Bicalho, E. K. Ganda, J. C. de Oliveira, G. Lorenzo, P. Trojacanec, and R. C. Bicalho. 2015. Prepartum and postpartum rumen fluid microbiomes: Characterization and correlation with production traits in dairy cows. Appl. Environ. Microbiol. 81:1327-1337. https://doi. org/10.1128/AEM.03138-14.

Littell, R. C., P. R. Henry, and C. B. Ammerman. 1998. Statistical analysis of repeated measures data using SAS procedures. J. Anim. Sci. 76:1216-1231.

Littell, R. C., G. A. Milliken, W. W. Stroup, R. D. Wolfinger, and O. Schabenberger. 2006. SAS for mixed models, 2nd ed. SAS Institute Inc., Cary, NC.

Lozupone, C. A., M. Hamady, S. T. Kelley, and R. Knight. 2007. Quantitative and qualitative $\beta$ diversity measures lead to different insights into factors that structure microbial communities. Appl. Environ. Microbiol. 73:1576-1585. https://doi.org/10.1128/ AEM.01996-06.

McCann, J. C., T. A. Wickersham, and J. J. Loor. 2014. Highthroughput methods redefine the rumen microbiome and its relationship with nutrition and metabolism. Bioinform. Biol. Insights 8:109-125. https://doi.org/10.4137/BBI.S15389.
Mohammed, R., D. M. Stevenson, P. J. Weimer, G. B. Penner, and K. A. Beauchemin. 2012. Individual animal variability in ruminal bacterial communities and ruminal acidosis in primiparous Holstein cows during the periparturient period. J. Dairy Sci. 95:67166730. https://doi.org/10.3168/jds.2012-5772.

Offner, A., A. Bach, and D. Sauvant. 2003. Quantitative review of in situ starch degradation in the rumen. Anim. Feed Sci. Technol. 106:81-93. https://doi.org/10.1016/S0377-8401(03)00038-5.

Petri, R. M., T. Schwaiger, G. B. Penner, K. A. Beauchemin, R. J. Forster, J. J. McKinnon, and T. A. McAllister. 2013. Characterization of the core rumen microbiome in cattle during transition from forage to concentrate as well as during and after an acidotic challenge. PLoS One 8:e83424. https://doi.org/10.1371/journal. pone.0083424.

Pitta, D. W., S. Kumar, B. Vecchiarelli, D. J. Shirley, K. Bittinger, L. D. Baker, J. D. Ferguson, and N. Thomsen. 2014. Temporal dynamics in the ruminal microbiome of dairy cows during the transition period. J. Anim. Sci. 92:4014-4022. https://doi.org/10.2527/ jas.2014-7621.

Poulsen, M., C. Schwab, B. Borg Jensen, R. M. Engberg, A. Spang, N. Canibe, O. Højberg, G. Milinovich, L. Fragner, C. Schleper, W. Weckwerth, P. Lund, A. Schramm, and T. Urich. 2013. Methylotrophic methanogenic Thermoplasmata implicated in reduced methane emissions from bovine rumen. Nat. Commun. 4:1428 https://doi.org/10.1038/ncomms2432.

Quast, C., E. Pruesse, P. Yilmaz, J. Gerken, T. Schweer, P. Yarza, J. Peplies, and F. O. Glöckner. 2013. The SILVA ribosomal RNA gene database project: Improved data processing and web-based tools. Nucleic Acids Res. 41:D590-D596. https://doi.org/10.1093/ nar/gks1219.

Ramiro-Garcia, J., G. Hermes, C. Giatsis, D. Sipkema, E. Zoetendal, P. Schaap, and H. Smidt. 2016. NG-Tax, a highly accurate and validated pipeline for analysis of $16 \mathrm{~S}$ rRNA amplicons from complex biomes. F1000 Res. 5:1791. https://doi.org/10.12688/ f1000research.9227.1.

Ransom-Jones, E., D. L. Jones, A. J. McCarthy, and J. E. McDonald. 2012. The Fibrobacteres: An important phylum of cellulose-degrading bacteria. Microb. Ecol. 63:267-281. https://doi.org/10.1007/ s00248-011-9998-1.

Rius, A. G., S. Kittelmann, K. A. Macdonald, G. C. Waghorn, P. H. Janssen, and E. Sikkema. 2012. Nitrogen metabolism and rumen microbial enumeration in lactating cows with divergent residual feed intake fed high-digestibility pasture. J. Dairy Sci. 95:50245034. https://doi.org/10.3168/jds.2012-5392.

Robinson, P. H., J. G. Fadel, and S. Tamminga. 1986. Evaluation of mathematical models to describe neutral detergent residue in terms of its susceptibility to degradation in the rumen. Anim. Feed Sci. Technol. 15:249-271. https://doi.org/10.1016/03778401(86)90079-9.

Seedorf, H., S. Kittelmann, G. Henderson, and P. H. Janssen. 2014. RIM-DB: A taxonomic framework for community structure analysis of methanogenic archaea from the rumen and other intestinal environments. PeerJ 2:e494 https://doi.org/10.7717/peerj.494.

Stensig, T., and P. H. Robinson. 1997. Digestion and passage kinetics of forage fiber in dairy cows as affected by fiber-free concentrate in the diet. J. Dairy Sci. 80:1339-1352. https://doi.org/10.3168/jds. S0022-0302(97)76062-4.

Stewart, C. S., H. J. Flint, and M. P. Bryant. 1997. The rumen bacteria. Pages 10-72 in The Rumen Microbial Ecosystem. 2nd. P. N. Hobson and C. S. Stewart, ed. Blackie Academic \& Professional, London, UK.

Tamminga, S., W. M. Van Straalen, A. P. J. Subnel, R. G. M. Meijer, A. Steg, C. J. G. Wever, and M. C. Blok. 1994. The Dutch protein evaluation system: the DVE/OEB-system. Livest. Prod. Sci. 40:139-155. https://doi.org/10.1016/0301-6226(94)90043-4.

Tas, B. M., H. Z. Taweel, H. J. Smit, A. Elgersma, J. Dijkstra, and S. Tamminga. 2006. Rumen degradation characteristics of perennial ryegrass cultivars during the growing season. Anim. Feed Sci. Technol. 131:103-120. https://doi.org/10.1016/j. anifeedsci.2006.02.002 
Tian, L., J. Scholte, K. Borewicz, B. van den Bogert, H. Smidt, A. J. W. Scheurink, H. Gruppen, and H. A. Schols. 2016. Effects of pectin supplementation on the fermentation patterns of different structural carbohydrates in rats. Mol. Nutr. Food Res. https://doi. org/10.1002/mnfr.201600149.

Towne, G., T. G. Nagaraja, C. Owensby, and D. Harmon. 1986 Ruminal evacuation's effect on microbial activity and ruminal function. J. Anim. Sci. 62:783-788. https://doi.org/10.2527/ jas1986.623783x.

van den Bogert, B., O. Erkus, J. Boekhorst, M. de Goffau, E. J. Smid, E. G. Zoetendal, and M. Kleerebezem. 2013. Diversity of human small intestinal Streptococcus and Veillonella populations. FEMS Microbiol. Ecol. 85:376-388. https://doi.org/10.1111/15746941.12127.

van Es, A. J. H. 1978. Feed evaluation for ruminants. I. The systems in use from May 1977 onwards in The Netherlands. Livest. Prod. Sci. 5:331-345. https://doi.org/10.1016/0301-6226(78)90029-5.

Van Soest, P. J., J. B. Robertson, and B. A. Lewis. 1991. Methods for dietary fiber, neutral detergent fiber, and nonstarch polysaccharides in relation to animal nutrition. J. Dairy Sci. 74:3583-3597. https://doi.org/10.3168/jds.S0022-0302(91)78551-2.
Vanzant, E. S., R. C. Cochran, and E. C. Titgemeyer. 1998. Standardization of in situ techniques for ruminant feedstuff evaluation. J. Anim. Sci. 76:2717-2729.

Wang, X., X. Li, C. Zhao, P. Hu, H. Chen, Z. Liu, G. Liu, and Z. Wang. 2012. Correlation between composition of the bacterial community and concentration of volatile fatty acids in the rumen during the transition period and ketosis in dairy cows. Appl. Environ. Microbiol. 78:2386-2392. https://doi.org/10.1128/AEM.07545-11.

Weimer, P. J. 2015. Redundancy, resilience, and host specificity of the ruminal microbiota: Implications for engineering improved ruminal fermentations. Front. Microbiol. 6:296. https://doi.org/10.3389/ fmicb.2015.00296.

Williams, A. G., and G. S. Coleman. 1992. The Rumen Protozoa. Springer-Verlag, New York, NY.

Zoetendal, E. G., C. C. G. M. Booijink, E. S. Klaassens, H. G. H. J. Heilig, M. Kleerebezem, H. Smidt, and W. M. de Vos. 2006. Isolation of RNA from bacterial samples of the human gastrointestinal tract. Nat. Protoc. 1:954-959. https://doi.org/10.1038/ nprot.2006.143. 